\title{
Evolving Role of Immunotherapy in Metastatic Castration Refractory Prostate Cancer
}

\author{
Nityam Rathi ${ }^{1} \cdot$ Taylor Ryan McFarland $^{1} \cdot$ Roberto Nussenzveig $^{1} \cdot$ Neeraj Agarwal $^{1} \cdot$ Umang Swami $^{1}$
}

Published online: 28 December 2020

(c) The Author(s) 2020

\begin{abstract}
Immunotherapies have shown remarkable success in the treatment of multiple cancer types; however, despite encouraging preclinical activity, registration trials of immunotherapy in prostate cancer have largely been unsuccessful. Sipuleucel-T remains the only approved immunotherapy for the treatment of asymptomatic or minimally symptomatic metastatic castrateresistant prostate cancer based on modest improvement in overall survival. This immune evasion in the case of prostate cancer has been attributed to tumor-intrinsic factors, an immunosuppressive tumor microenvironment, and host factors, which ultimately make it an inert 'cold' tumor. Recently, multiple approaches have been investigated to turn prostate cancer into a 'hot' tumor. Antibodies directed against programmed cell death protein 1 have a tumor agnostic approval for a small minority of patients with microsatellite instability-high or mismatch repair-deficient metastatic prostate cancer. Herein, we present an overview of the current immunotherapy landscape in metastatic castration-resistant prostate cancer with a focus on immune checkpoint inhibitors. We describe the results of clinical trials of immune checkpoint inhibitors in patients with metastatic castration-resistant prostate cancer; either as single agents or in combination with other checkpoint inhibitors, poly (ADP-ribose) polymerase (PARP) inhibitors, tyrosine kinase inhibitors, novel hormonal therapies, chemotherapies, and radioligands. Finally, we review upcoming immunotherapies, including novel monoclonal antibodies, chimeric-antigen receptor (CAR) T cells, Bi-Specific T cell Engagers (BiTEs), therapies targeting the adenosine pathway, and other miscellaneous agents.
\end{abstract}

\section{Introduction}

Immunotherapies have changed the treatment landscape of cancer but have historically shown limited efficacy in prostate cancer, which is generally considered an immunologically cold tumor [1]. This immune unresponsiveness is attributed to a combination of intrinsic factors in prostate cancer, its immunosuppressive microenvironment, and host physiological factors such as age and hormonal influence [1]. Multiple tumor-intrinsic factors, such as loss of PTEN,

Nityam Rathi and Taylor Ryan McFarland contributed equally to this work.

Umang Swami

umang.swami@hci.utah.edu

Neeraj Agarwal

neeraj.agarwal@hci.utah.edu

1 Division of Oncology, Department of Internal Medicine, Huntsman Cancer Institute, University of Utah, 2000 Circle of Hope Drive Suite 5726, Salt Lake City, UT 84112, USA

\section{Key Points}

The field of immunotherapy in prostate cancer has lagged behind other cancer types where multiple immunotherapeutic agents have been approved over the last decade.

Sipuleucel-T is the only immunotherapy approved in the setting of metastatic prostate cancer, and is associated with modest survival benefit.

Based on the results of early-phase trials of several novel immunotherapy-based regimens, it is likely that the treatment paradigm of metastatic castration refractory prostate cancer is going to be revolutionized in the near future. Some of the promising agents or regimens include the combination of immune check point inhibitors with cabozantinib or poly(ADP-ribose) polymerase (PARP) inhibitors, novel radioimmune agents, monoclonal antibodies, chimeric-antigen receptor (CAR) T cells, and Bi-Specific T-cell Engagers (BiTEs). 
altered interferon-1 signaling, decreased major histocompatibility complex (MHC) class I (MHC-1) expression, low tumor-associated antigen expression, low tumor mutational burden, and decreased incidence of DNA damage repair defects, make prostate cancer immunologically inert [1]. Therefore, a huge focus is being placed on the development of novel immunotherapy in the form of novel combinatorial regimens.

Herein, we review the role of immunotherapy in the treatment of metastatic castration-resistant prostate cancer (mCRPC). We begin with a discussion of vaccine-based approaches, followed by an examination of ongoing investigations of immune checkpoint inhibitors as monotherapies and in novel therapeutic combinations. We conclude with a summary of updates on novel agents, which will likely influence the future of immunotherapy in mCRPC. Selected ongoing clinical trials are summarized in Table 1, and Fig. 1 provides a synopsis of the mechanisms of action of various immune agents.

\section{Early Immunotherapies: Cancer Vaccines}

Previous immunotherapies for mCRPC consisted primarily of the cancer treatment vaccines PROSTVAC and Sipuleucel-T (Provenge ${ }^{\circledR}$ ). Although not designed to be curative or preventative agents, these vaccine treatments are believed to engage the immune system and induce a cell-mediated response, driven primarily by $\mathrm{T}$ cells, against pre-existing prostate cancer.

\subsection{PROSTVAC}

PROSTVAC is a genetically engineered poxvirus that contains transgenes for prostate-specific antigen (PSA) and a synergistic triad of T-cell costimulatory molecules, collectively designated as TRICOM, which includes ICAM-1 (CD54), B7.1 (CD80), and LFA-3 (CD58) [2-4]. This unique approach induces T-cell activation with the PSA epitope $[5,6]$, followed by an enhancement of antitumor activity upon engagement of TRICOM [4].

In a phase I study of $42 \mathrm{mCRPC}$ patients, PROSTVAC treatment led to an increase in the proportion of active PSAspecific $\mathrm{T}$ cells, and was associated with a low-toxicity profile of erythema, tenderness, and vesicle formation at the site of injection [7]. In a second phase I trial of $15 \mathrm{mCRPC}$ patients, PSA-specific immune responses were observed in four of six HLA-A2 + patients, and a decrease in PSA velocity was seen in 9 of 15 patients [8]. A phase II trial randomized 125 minimally symptomatic mCRPC patients $2: 1$ to receive PROSTVAC or a control vector. The primary endpoint of progression-free survival (PFS) was similar in both groups (stratified log-rank $p$ value $=0.6$ ). However, a significant improvement in median overall survival was observed
(OS; 25.1 months vs. 16.6 months; hazard ratio [HR] 0.56, 95\% confidence interval $[\mathrm{CI}] 0.37-0.85 ; p=0.0061)$. Again, PROSTVAC was well-tolerated, with low-grade adverse events (AE) of fatigue, fever, and nausea [9].

This improvement in OS led to a phase III study to further investigate these findings [10]. A total of $1297 \mathrm{mCRPC}$ patients were randomized to receive PROSTVAC (arm V, $n=432$ ), PROSTVAC plus granulocyte-macrophage colonystimulating factor (GM-CSF; arm VG, $n=432$ ), or placebo (arm P, $n=433$ ), with a primary endpoint of OS and secondary endpoints of patients alive without the following events at 6 months: radiographic progression, pain progression, chemotherapy initiation, or death [10]. The trial was terminated prematurely as no significant effect on median OS was identified (arm V: 34.4 months; arm VG: 33.2 months; arm P: 34.3 months). Compared with placebo, the HR for Arm V was 1.01 (95\% CI $0.84-1.20 ; p=0.47)$, and 1.02 (95\% CI 0.86-1.22; $p=0.59$ ) for Arm VG. There was also no significant difference in the percentage of patients alive without the above-mentioned events (arm V: 29.4\%; arm VG: 28.0\%; arm P: 30.3\%) [10].

\subsection{Sipuleucel-T}

Sipuleucel-T (Provenge ${ }^{\circledR}$ ) is an autologous cellular immunotherapy consisting of peripheral blood mononuclear cells enriched for dendritic cell fraction, which are activated ex vivo with PA2024 (prostatic acid phosphatase and granulocyte-stimulating factor fusion protein) and then reinfused into the patient to stimulate antigen-specific $T$ cells [11].

Given the promising findings in early-phase studies, phase III trials were initiated. In the placebo-controlled D9901 trial, 127 patients with mCRPC were randomized in a 2:1 ratio to receive sipuleucel-T $(n=82)$ or placebo $(n=45)$. The results demonstrated an improved median OS with sipuleucel-T when compared with placebo (25.9 months vs. 21.4 months; HR $1.71,95 \%$ CI 1.13-2.58; $p=0.01$ ). Another identical trial, D9902A, was stopped before the availability of survival results based on initial disease progression results in D9901. In a pooled analysis of both D9901 and D9902A, sipuleucel-T showed an improved median OS compared with placebo (23.2 months vs. 18.9 months; HR $1.50,95 \%$ CI $1.10-2.05 ; p=0.011$ ) [12]. However, these studies did not show a significant improvement in time to disease progression, which was the primary endpoint in both trials. Therefore, a placebo-controlled, phase III study, IMPACT, was conducted with OS as the primary endpoint [13]. Overall, 512 mCRPC patients were randomized in a 2:1 ratio to sipuleucel-T $(n=341)$ or placebo $(n=171)$ [13]. Sipuleucel-T demonstrated a significant improvement in median OS compared with placebo (25.8 months vs. 21.7 months; adjusted HR $0.78,95 \%$ CI $0.61-0.98 ; p=0.03$ ). Again, no differences with objective or clinical disease progression were observed 


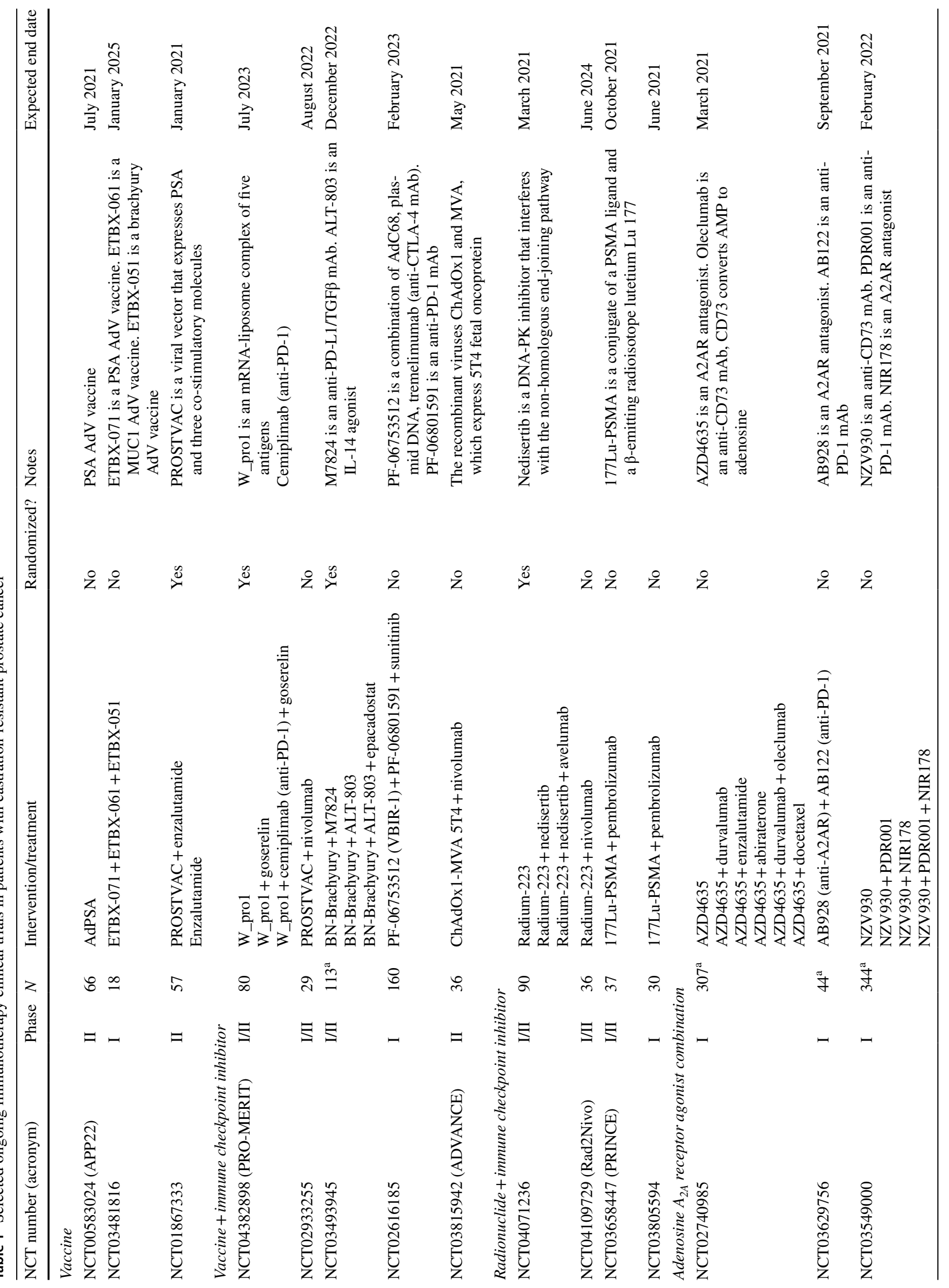




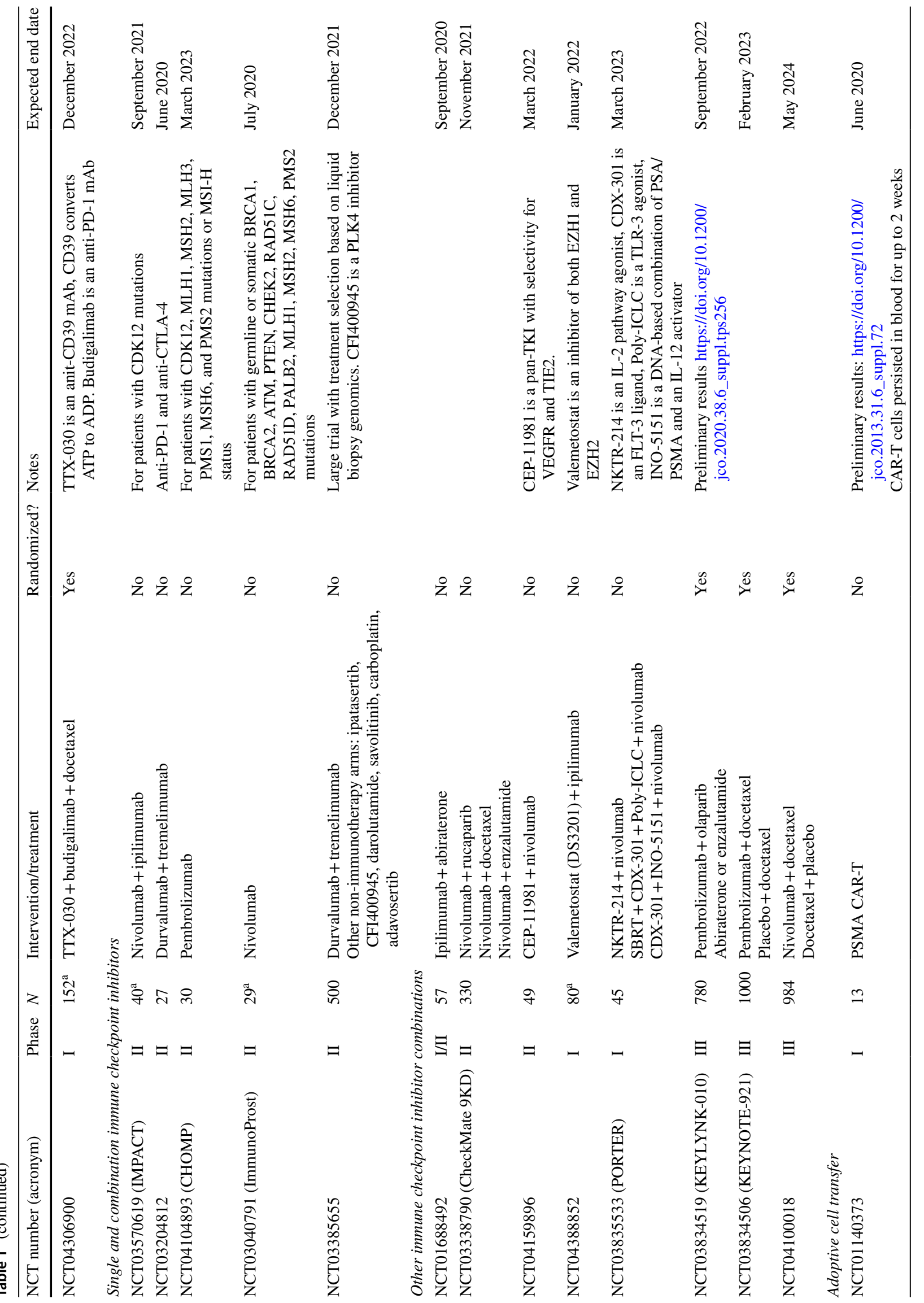




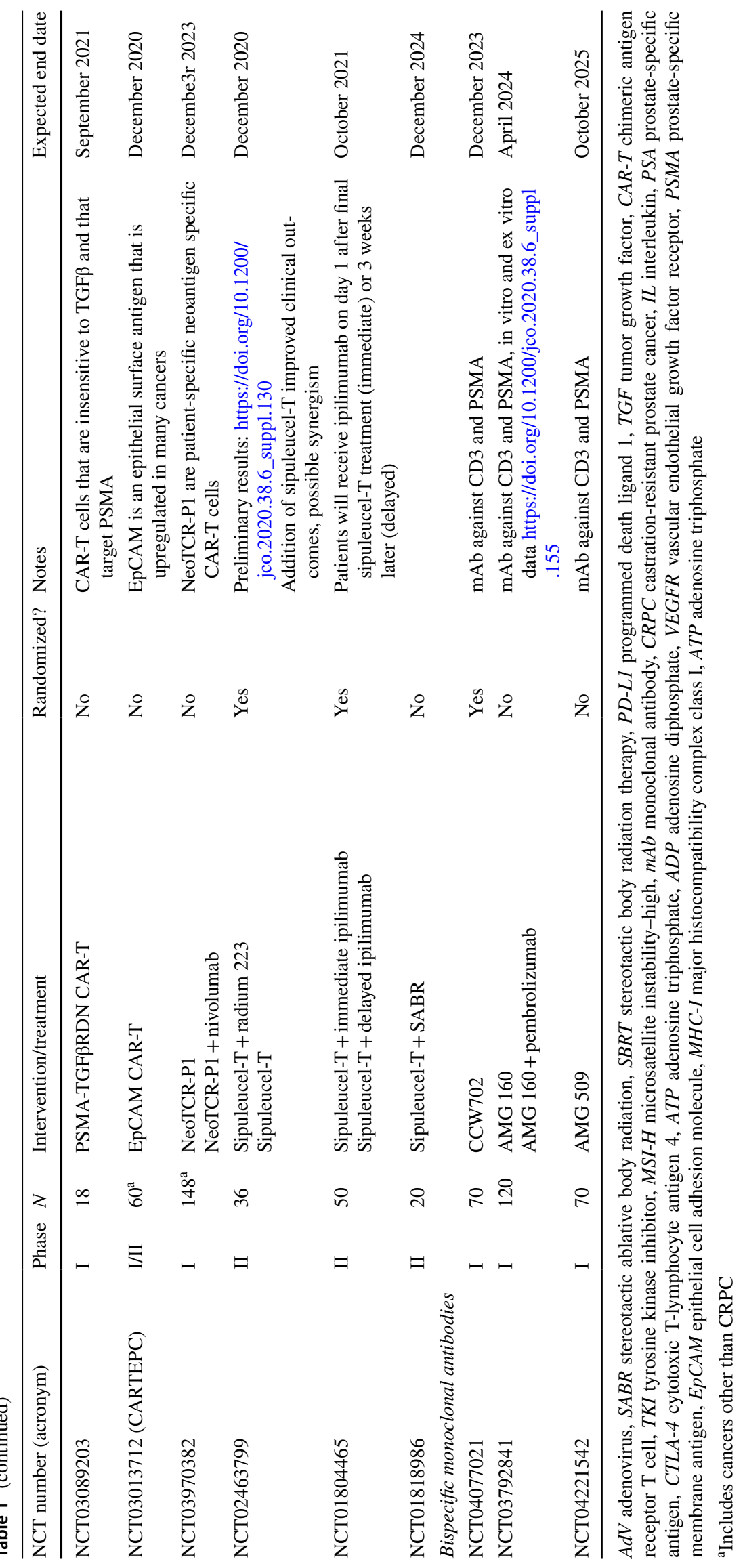




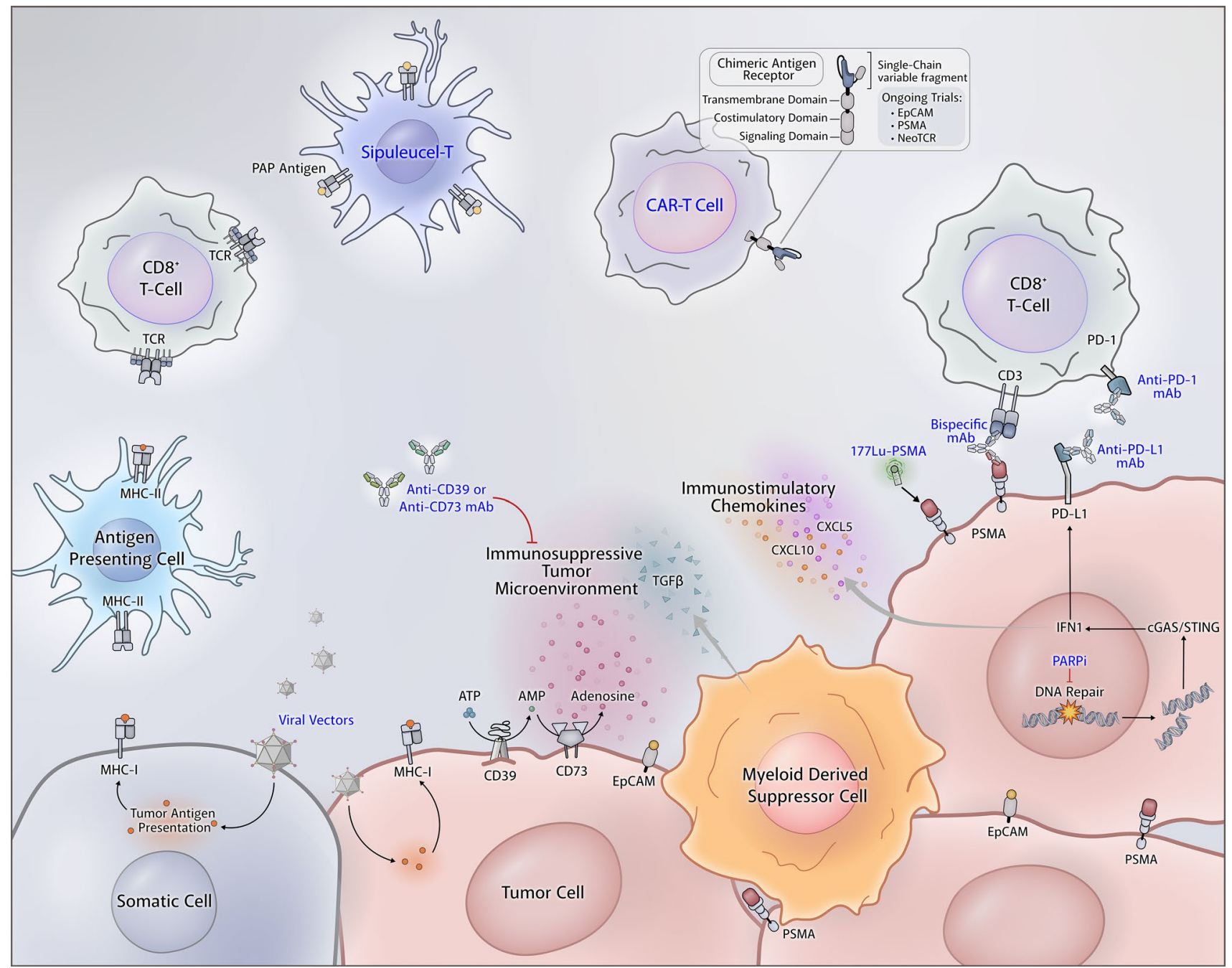

Fig. 1 An overview of immune system pathways and targets in prostate cancer. Tumor specific-antigens from viral vectors (e.g. PROSTVAC) are displayed on MHCs. Prostate cancer cells often express unique markers such as PSMA that are targetable with CAR-Ts. Patient-specific neoantigens are also potential targets with custom NeoTCRs. Other cell-mediated therapies, such as Sipuleucel-T, use prostate cancer-specific antigen-presenting cells displaying PAP to stimulate the immune system. Increased levels of extracellular adenosine, myeloid-derived suppressor cells, and immune checkpoints such as PD-1/PD-L1 prevent anti-tumor immunity but are also targetable with various monoclonal antibodies. Use of PARPi can cause the cells to not only increase chemokine production but also increase

[13]. Based on these results, sipuleucel-T was approved by the US FDA for the treatment of men with mCRPC with asymptomatic or minimally symptomatic disease. Currently, the treatment is only available in the US. A study conducted under contract to the Agency for Healthcare Research and Quality was of the opinion that these phase III trial designs had an inherent potential for confounding due to differences in post-progression treatment, making estimates of the actual benefit with sipuleucel-T less certain [14].
PD-L1 expression. MHCs major histocompatibility complexes, PSMA prostate-specific membrane antigen, $C A R-T s$ chimeric antigen receptor $\mathrm{T}$ cells, NeoTCRs neoantigen T-cell receptors, PAP prostatic acid phosphatase, $P D-1$ programmed cell death protein $1, P D-L 1$ programmed cell death ligand $1, P A R P$ poly(ADP ribose) polymerase, PARPi PARP inhibitor, $m A b$ monoclonal antibody, $T G F$ tumor growth factor, EPCAM epithelial cell adhesion molecule, $M H C-I$ major histocompatibility complex class I, ATP adenosine triphosphate, $A M P$ adenosine monophosphate, IFN 1 interferon 1, cGAS/ STING cyclic GMP-AMP Synthase/Stimulator of Interferon Genes, $T G F-\beta$ transforming growth factor beta

In a post hoc subgroup analysis [15] of OS by age from these phase III trials, there was an 11-month OS difference in the placebo group between patients younger than 65 years of age and patients $\geq 65$ years of age ( 28.2 vs. 17.2 months; $p<0.01)$. This was surprising as age is not prognostic for OS in mCRPC patients. In the IMPACT study, OS benefit by sipuleucel-T seemed to be derived entirely from the older patient cohort ( $<65$ years of age: HR $1.41,95 \%$ CI $0.87-2.29$ vs. $\geq 65$ years: HR $0.58,95 \%$ CI $0.43-0.76$ ). 
Patients $<65$ years of age in whom sipuleucel-T did not appear to be effective, appeared to live longer, with a median OS of 29 months compared with patients $\geq 65$ years of age in whom the intervention appeared to be effective (median OS of 23.4 months). There have been concerns regarding the apparent shorter OS of older patients in the placebo arm, along with speculation regarding the detrimental effect of placebo intervention [15]. At present, sipuleucel-T is recommended only for asymptomatic or minimally symptomatic mCRPC patients with no liver metastasis, Eastern Cooperative Oncology Group (ECOG) performance status of $0-1$, and life expectancy of more than 6 months. It is not recommended for patients with small-cell/neuroendocrine histology [16].

NCT03024216 is a phase Ib study that randomized asymptomatic or minimally symptomatic progressive mCRPC patients who met the standard criteria for sipuleucel-T to either atezolizumab (1200 mg intravenously every 3 weeks) for two doses followed by sipuleucel-T every 2 weeks for a total of three infusions (Arm 1), or sipuleucel$\mathrm{T}$ every 2 weeks for three infusions followed by atezolizumab (1200 mg intravenously every 3 weeks) for two doses (Arm 2) [17]. The primary endpoint was safety. Available results from 37 enrolled patients showed a median PFS of 8.2 months in Arm 1 and 5.8 months in Arm $2(p=0.054)$. No grade $3 / 4$ immune-related toxicities were observed [17].

\section{Immune Checkpoint Inhibitors: Monotherapy}

Immune checkpoints regulate immune pathways that maintain self-tolerance and limit immune-related collateral tissue damage with infections. These pathways are exploited by cancer cells to evade anti-tumor immunological responses by downregulating T-cell activity and creating an immunosuppressive environment [18]. Antibodies directed against cytotoxic T-lymphocyte-associated protein 4 (CTLA-4), programmed cell death protein 1 (PD-1), or its ligand (PDL1) have received FDA approval for multiple tumor types and have been assessed in mCRPC as discussed below [18].

\subsection{Ipilimumab}

Ipilimumab is a fully human immunoglobulin (Ig) G1 monoclonal antibody that inhibits CTLA-4 [18]. In human tumor tissues, CTLA-4 blockade has been associated with an increased density of intratumoral CD4+ and CD8 + cells without depletion of regulatory T cells [19]. Early-phase clinical trials established ipilimumab as a safe and tolerable treatment in the mCRPC setting. A phase I study of 30 mCRPC patients, of whom 24 were chemotherapy-naïve, did not identify any dose-limiting toxic effects upon treatment with escalating doses of ipilimumab in combination with a fixed dose of PROSTVAC [20]. Additional phase I and I/ II studies of mCRPC patients further confirmed the clinical potential of ipilimumab treatment, with common grade 3 or 4 immune-related AEs of diarrhea, colitis, rash, and hepatitis [20-22].

Based on these findings, the phase III CA184-043 trial was initiated to assess the efficacy of ipilimumab after radiotherapy in $\mathrm{mCRPC}$ patients who had progressed on docetaxel. Overall, 799 patients were randomized in a 1:1 ratio to receive ipilimumab $(n=399)$ or placebo $(n=400)$. The primary endpoint was OS in the intent-to-treat population [23]. The results did not show a significant difference in median OS between both treatment groups. The median OS with ipilimumab was 11.2 months, compared with 10.0 months with placebo (HR $0.85,95 \%$ CI $0.72-1.00$; $p=0.053)$. The rates of all-grade and grade $3 / 4$ immunerelated AEs with ipilimumab were $63 \%$ and $26 \%$, respectively [23]. In a recently reported preplanned long-term analysis, OS was significantly improved with ipilimumab [24]. OS rates in the ipilimumab arm were higher at 3 years (15.3\% vs. $7.9 \%), 4$ years ( $10.1 \%$ vs. $3.3 \%)$, and 5 years (7.9\% vs. $2.7 \%$ ) compared with placebo [24]; however, these data were analyzed after the primary OS analysis and hence must be considered as hypothesis-generating and not definitive.

\subsection{Pembrolizumab}

Pembrolizumab is a humanized IgG4 monoclonal antibody that binds to the PD-1 receptor and blocks its interaction with PD-L1, leading to the counteraction of immune evasion by cancer cells [18]. In two independent cohorts with primary prostate cancer, moderate to high PD-L1 expression was observed in $>50 \%$ of the samples and was associated with shorter time to biochemical recurrence [25]. In the phase Ib KEYNOTE-028 trial, 23 mCRPC patients with measurable disease and PD-L1 expression in $\geq 1 \%$ of tumor or stromal cells were treated with pembrolizumab. The ORR was $17.4 \%$, median PFS was 3.5 months, and the median OS was 7.9 months [26].

The phase II KEYNOTE-199 study enrolled mCRPC patients previously treated with docetaxel and one or more targeted endocrine therapies in five cohorts based on clinical and molecular disease characteristics. Patients in cohorts 1,2 , and 3 were treated with pembrolizumab. Cohort 1 $(n=133)$ included PD-L1 + (defined as combined positivity score $[\mathrm{CPS}] \geq 1$ ) patients with measurable disease, cohort 2 $(n=66)$ included PD-L1 - patients with measurable disease, and cohort $3(n=59)$ included patients with bone-predominant disease regardless of PD-L1 status [27]. The primary endpoint was ORR in cohorts 1 and 2, both separately and combined. Across all cohorts, pembrolizumab showed 
acceptable safety but limited antitumor activity. The ORR was $5 \%$ in cohort 1 and $3 \%$ in cohort 2 . The median duration of response (DOR) was not reached in cohort 1 and was 10.6 months in cohort 2 . The disease control rate (DCR) and median OS were $10 \%$ and 9.5 months, respectively, in cohort $1,9 \%$ and 7.9 months in cohort 2 , and $22 \%$ and 14.1 months in cohort 3 [27]. ORR was $11 \%$ in patients with BRCA1/2 or ATM aberrations, compared with $3 \%$ in patients without any homologous recombination repair (HRR) defects [27]. Tumor mutational burden and PD-L1 status were associated with better PSA response [28].

\section{Immune Checkpoint Inhibitors: Combination Therapies}

\subsection{Nivolumab + Ipilimumab}

Nivolumab is a fully human IgG4 monoclonal antibody that inhibits the PD-1 receptor [18]. Preclinical and clinical studies have suggested a synergistic effect of anti-PD-1 and antiCTLA-4 antibodies, which has led to the exploration of this combination in mCRPC [29-32]. CheckMate 650 is a phase II study of nivolumab plus ipilimumab in asymptomatic/ minimally symptomatic mCRPC patients, with primary endpoints of ORR and radiographic PFS, and a secondary endpoint of safety [33]. Interim results showed an ORR of $26 \%$ in chemotherapy-naïve patients with measurable disease and $10 \%$ in patients with measurable disease who have progressed on taxane-based chemotherapy [33].

\subsection{Immune Checkpoint Inhibitors with Poly(ADP ribose) Polymerase (PARP) Inhibitors}

Poly(ADP ribose) polymerase (PARP) is recruited to sites of DNA damage and catalyzes ADP ribosylation reactions essential to DNA repair mechanisms, such as HRR and base excision repair, to avoid cell cycle arrest [34]. PARP inhibition results in unrepaired DNA breaks leading to genomic instability, thereby causing cell death. In tumors with BRCA1 and 2 deleterious alterations, PARP inhibitors lead to synthetic lethality. PARP inhibitors also trap PARP 1 and 2 enzymes at damaged DNA, and these trapped PARP-DNA complexes are much more cytotoxic than single-strand breaks due to PARP inactivation [35]. About $11.8 \%$ of patients with metastatic prostate cancer have germline mutations in DNA-repair genes, while $19.3 \%$ of mCRPC patients have an aberration in BRCA2, BRCA1, or ATM genes [36, 37]. In a prospective genomic analysis of 1033 patients, $3.1 \%$ of mCRPC patients demonstrated phenotypic evidence of microsatellite instability-high (MSI$\mathrm{H}$ ) or mismatch repair-deficient (dMMR) solid tumors [38].
Additionally, among 11 MSI-H/dMMR mCRPC patients treated with immune checkpoint inhibitors, six $(54.5 \%)$ had a $>50 \%$ decline in PSA levels, of whom four had radiographic responses [38].

Two PARP inhibitors, olaparib and rucaparib, have received FDA approval for $\mathrm{MCRPC}$ patients with deleterious or suspected deleterious germline or somatic HRR or BRCA 1 and 2 mutations, respectively [39]. PARP inhibitors were recently found to trigger antitumor immunity through stimulator of interferon genes (STING) activation, which is followed by the upregulation of chemokines that recruit $\mathrm{T}$ cells [40]. As PD-L1 is also upregulated, the antitumor response can be amplified with therapies targeting the PD-1 axis [41]. Several clinical trials are currently underway to assess the efficacy of immune checkpoints in combination with PARP inhibitors.

\subsubsection{Pembrolizumab + Olaparib}

Cohort A of KEYNOTE 365 is evaluating pembrolizumab in combination with olaparib in $\mathrm{mCRPC}$ patients previously treated with docetaxel and up to two novel hormonal therapies (NHTs) [42]. The primary endpoints of this phase $\mathrm{Ib} / \mathrm{II}$ trial are safety and PSA response rate, and secondary endpoints are ORR, OS, PFS, and time to PSA progression. Available results from 84 treated patients showed a PSA response rate of $9 \%$, ORR of $8.3 \%$, a median time to PSA progression of 16 weeks, median radiographic PFS of 4 months, and median OS of 14 months [42]. In a subgroup analysis, the T-cell-inflamed gene expression profile was not associated with ORR or PSA response [43].

KEYLYNK-010 (NCT03834519) is a phase III study evaluating the efficacy and safety of pembrolizumab in combination with olaparib in molecularly unselected mCRPC patients who have progressed on an NHT (abiraterone or enzalutamide) and docetaxel [44]. Patients will be randomized in a 2:1 ratio to the experimental arm or alternate NHT. Primary endpoints are OS and radiological PFS, and secondary endpoints are the time to initiation of subsequent anticancer therapy, ORR, and DOR. The anticipated study completion date is 30 September 2022 [44].

\subsubsection{Nivolumab + Rucaparib}

Cohort A of the phase II CheckMate 9KD trial (NCT03338790) is evaluating the combination of nivolumab with rucaparib in patients with mCRPC [45]. Primary endpoints of the study include ORR and PSA response rate, and secondary endpoints are OS, PFS, response kinetics, and safety [45]. The study is projected to reach its completion in 2021. 


\subsubsection{Durvalumab + Olaparib}

A phase II study evaluated durvalumab, a human IgG1$\mathrm{K}$ monoclonal antibody, in combination with olaparib in patients with mCRPC who had prior treatment with at least one NHT. Of the 17 patients enrolled, median radiographic PFS was 16.1 months, and 53\% (9 of 17) of patients had a radiological and/or PSA response (95\% CI 4.5-16.1 months), with a 12-month radiographic PFS of $51.5 \%$ (95\% CI 25.7-72.3\%). The trial was enriched with patients with germline or somatic alterations in DNA damage repair genes, and the median radiographic PFS in these patients was 16.1 months [46].

\subsection{Immune Checkpoint Inhibitors with Tyrosine Kinase Inhibitors}

Proangiogenic factors, which are often produced in response to hypoxia or oncoproteins, such as vascular endothelial growth factor (VEGF) and hepatocyte growth factor, are known to modulate immunity by inducing regulatory $\mathrm{T}$ cells and inhibiting the maturation of dendritic cells [47-49]. These mechanisms decrease T-cell infiltration into the tumor milieu. Antiangiogenic agents that inhibit VEGF/VEGF receptors have shown to reverse the tumor-induced immune suppression by altering the tumor microenvironment [50, 51]. Cabozantinib is a multikinase inhibitor that targets MET, RET, AXL, and VEGF receptor 2, which are central to tumor cell proliferation and angiogenesis [52, 53]. In preclinical models, cabozantinib, alone or in combination with a cancer vaccine, sensitized tumor cells to immune-mediated killing by reducing the function of regulatory $\mathrm{T}$ cells and amplifying cytokine production from effector T cells [54]. These findings have led to the evaluation of cabozantinib with immunotherapy in patients with mCRPC.

\subsubsection{Atezolizumab + Cabozantinib}

In cohort six of the phase Ib COSMIC-021 trial, cabozantinib was evaluated in combination with atezolizumab, a PD-L1 inhibitor in patients with mCRPC [55]. As of October 2019, 44 mCRPC patients were enrolled to receive the combination regimen [55]. The combination demonstrated significant clinical activity, with an ORR of $32 \%$, a DCR of $80 \%$, and a median DOR of 8.3 months [55]. The combination was safe, with common AEs of fatigue, nausea, and decreased appetite [55]. Based on these encouraging results, the combination is being evaluated in a phase III trial (CONTACT-02, NCT04446117). The study will be randomizing 580 patients with mCRPC who have progressed on an NHT in a 1:1 ratio to the combination of cabozantinib with atezolizumab or alternate NHT (abiraterone or enzalutamide).

\subsection{Immune Checkpoint Inhibitors with Novel Hormonal Therapies}

The initiation and progression of prostate cancer are heavily dependent on the androgen receptor (AR) signaling pathway [56]. Enzalutamide is an AR antagonist that competitively inhibits the binding of androgens to AR, nuclear translocation of AR, and AR binding to chromosomal DNA [57]. Enzalutamide has demonstrated to improve OS in both docetaxel-naïve and pretreated mCRPC patients $[58,59]$. In preclinical studies, enzalutamide has shown to not only inhibit the proliferation of prostate cancer cells, but also to increase their sensitivity to cytotoxic T-lymphocyte-mediated killing $[60,61]$, thus proving the rationale for its combination with immunotherapies in mCRPC.

\subsubsection{Pembrolizumab + Enzalutamide}

Cohorts 4 and 5 of KEYNOTE 199 evaluated pembrolizumab with enzalutamide in patients with chemotherapynaïve and enzalutamide refractory mCRPC patients. Cohort 4 included patients with measurable disease, while cohort 5 included patients with bone-predominant disease. In cohort 4 , the ORR (primary endpoint) was $12 \%$ and the DCR was $51 \%$. In cohort 5, the DCR was $51 \%$ [62].

Cohort $\mathrm{C}$ of the phase $\mathrm{Ib} / \mathrm{II}$ clinical trial KEYNOTE 365 is evaluating the combination of pembrolizumab with enzalutamide in patients with mCRPC who were intolerant to or had progression on abiraterone [63]. The primary endpoints were PSA response rate, ORR, and safety. Available results from 103 enrolled patients showed a PSA response rate of $22 \%$. In patients with measurable disease and $\geq 27$ weeks of follow-up, the ORR was $12 \%$, and the DCR was $32 \%$. Median DOR has not yet been reached, radiological PFS was 6.1 months, and median OS was 20.4 months [63]. A T-cell-inflamed gene expression profile was not significantly associated with ORR or PSA response [63]. The combination is being evaluated in the phase III KEYNOTE-641 (NCT03834493) study in patients with mCRPC [63].

\subsubsection{Nivolumab + Enzalutamide}

CheckMate 9KD (cohort C) is a phase II trial evaluating the nivolumab + enzalutamide combination in MCRPC patients [45]. Results are anticipated in 2021.

\subsubsection{Atezolizumab+Enzalutamide}

IMbassador 250 was a randomized, phase III study that compared the safety and efficacy of atezolizumab with enzalutamide in patients with mCRPC who previously progressed on abiraterone and docetaxel, or were ineligible to receive 
taxane-based chemotherapy. The trial enrolled 759 patients who were randomized in a 1:1 ratio to atezolizumab with enzalutamide $(n=379)$ or enzalutamide alone $(n=380)$; however, the study was terminated early upon failure of the experimental arm to improve OS (15.2 months with combination vs. 16.6 months enzalutamide alone; HR 1.12, 95\% CI $0.91-1.37 ; p=0.28$ ) [64].

\subsection{Immune Checkpoint Inhibitors with Docetaxel}

Docetaxel has been shown to improve OS in mCRPC patients [65]. It inhibits microtubular depolymerization, thereby arresting dividing cells in the G2-M phase, and induces BCL2 phosphorylation that ultimately leads to apoptosis [66]. Docetaxel has also demonstrated immunomodulatory effects, by rendering tumor cells more sensitive to immune-mediated killing by enhanced cytotoxic $\mathrm{T}$ lymphocyte lysis [67, 68]. Additionally, docetaxel has been found to augment MHC-I expression and loading, as well as to enhance the release of potent cancer antigens following the degradation of cancer cells $[68,69]$. When administered following or in combination with cancer vaccines, docetaxel has shown to increase antitumor activity as a result of more robust antigen-specific T-cell responses, with significant decreases in tumor volume [70]. These findings generated considerable enthusiasm to combine docetaxel with immune checkpoints.

\subsubsection{Pembrolizumab + Docetaxel}

Cohort B of the phase Ib/II KEYNOTE 365 study evaluated the efficacy of the pembrolizumab with docetaxel combination in patients with mCRPC who had progression or were intolerant to NHT. The primary endpoints were safety, PSA response rate, and ORR [71]. Among the 104 treated patients, the PSA response rate was $28 \%$, ORR was $18 \%$, and DCR was $51 \%$. The median radiographic PFS, time to PSA progression, and OS were 8.3 months, 6.2 months, and 20.4 months, respectively. The most common treatmentrelated AEs $(\geq 30 \%)$ were alopecia, diarrhea, and fatigue. Again, T-cell-inflamed gene expression profile was not associated with ORR or PSA response [71]. The combination is currently being evaluated in the phase III KEYNOTE 921 (NCT03834506) trial, with a projected study completion in 2023 [71].

\subsubsection{Nivolumab + Docetaxel}

CheckMate 9KD (cohort B) is a phase II trial evaluating nivolumab in combination with docetaxel in patients with mCRPC [72]. Co-primary endpoints are ORR and PSA response rate. At an interim analysis of 41 patients, the combination showed an ORR of $36.8 \%$, PSA response rate of $46.3 \%$, and median radiographic PFS of 8.2 months. The safety profile was consistent with those of individual agents [72]. A phase III randomized trial, CheckMate 7DX (NCT04100018), is further evaluating the combination in patients with mCRPC, with primary endpoints of radiographic PFS and OS.

\section{Immune Checkpoint Inhibitors with ${ }^{177}$ Lu-PSMA-617 Radioligand Therapy}

${ }^{177} \mathrm{Lu}$-PSMA-617 is a radioligand composed of Lutetium-177, a therapeutic radionuclide that primarily emits $\beta$ radiation, and PSMA-617, a high-affinity ligand of human prostate-specific membrane antigen (PSMA) [73, 74]. PSMA-617 binds to PSMA, an antigen that is overexpressed in prostate cancer, followed by its internalization into the cancer cell $[75,76]$. Therefore, by utilizing a targeted approach, PSMA- 617 directs the $\beta$ radiation from ${ }^{177} \mathrm{Lu}$ to the tumor site, thereby attempting to avoid exposure to the rest of the body. Currently, a phase Ib trial of 30 patients (NCT03805594) and a phase Ib/II trial of 37 patients (PRINCE; NCT03658447) are investigating the potential safety and efficacy of ${ }^{177}$ Lu-PSMA-617 in combination with pembrolizumab in patients with mCRPC. Both studies are anticipated to complete in 2021.

\section{Promising Future Directions}

\subsection{Targeting Soluble MIC with Novel Monoclonal Antibodies}

The expression of major histocompatibility I chain-related molecule (MIC) is upregulated on most epithelial cells during times of stress, including the early stages of prostate cancer [77]. Membrane-bound MIC interacts with NKG2D expressed on $\mathrm{T}$ and natural killer (NK) cells to trigger immune activation [78, 79]. Membrane-bound MIC is cleaved by proteases as cancer progresses, resulting in tumor-derived soluble MIC (sMIC), which binds to NKG2D and induces endocytosis and degradation of NKG2D, thereby suppressing the NK and tumor antigen-specific T-cell response [80, 81]. A significant increase in sMIC and a deficiency in NK cell function have been reported among advanced prostate cancer patients [82]. In preclinical studies, targeting sMIC with monoclonal antibodies has been found to invigorate antitumor immune responses, eliminate primary and metastatic tumors, and sensitize prostate tumors to CTLA-4 and PD-1/PD-L1 blockade therapy [83-86]. The potential clinical efficacy of a combination treatment including anti-sMIC and immune checkpoints still needs to be explored. 


\subsection{Prostate-Specific Membrane Antigen (PSMA)-Directed Chimeric Antigen Receptor (CAR) T-Cell Therapy}

Chimeric antigen receptor (CAR) $\mathrm{T}$ cells (CAR-Ts) are genetically engineered $\mathrm{T}$ cells consisting of a fusion protein that contains an extracellular component of a monoclonal antibody variable fragment, which improves affinity and specificity toward an antigen, and a T-cell receptor intracellular signaling domain(s), which relays costimulatory signals $[87,88]$. CARs are thus able to simulate T-cell recognition and activity without the limitations of reduced MHC-associated antigen presentation and expression, which is one of the major mechanisms of immunoevasion by tumor cells [89]. CAR-Ts have transformed the treatment landscape for leukemia and are now gaining traction in solid tumors [90, 91]. In preclinical studies, the transfer of a CAR designed to target PSMA into tumor-bearing mice led to significant eradication of the neoplasia [88].

PSMA-targeted CAR-Ts in $\mathrm{mCRPC}$ have since been investigated in a phase I dose-escalating trial (NCT01140373). At interim analysis, of the four patients receiving an infusion of $1 \times 10^{7} \mathrm{CAR}-\mathrm{Ts} / \mathrm{kg}$, one patient had stable disease for $>6$ months and a second patient had stable disease for $>16$ months, while the third and fourth patients progressed [92]. Further results are awaited.

Transforming growth factor (TGF)- $\beta$ causes immunosuppression in the tumor microenvironment by inhibiting T-cell proliferation, NK cell function, and antigen presentation, and thereby plays a role in the progression of prostate cancer [93, 94]. In mouse models, co-expression of a null TGF $\beta$ receptor enhanced the potency of PSMA-directed CAR-Ts, as evidenced by increased proliferation of $\mathrm{T}$ cells, enhanced cytokine secretion, long-term persistence of immune cells, and tumor eradication [95]. A phase I clinical trial (NCT03089203) is evaluating the safety and efficacy of PSMA-directed/TGF $\beta$-insensitive CAR-Ts in patients with mCRPC [96].

Other notable CAR-Ts in clinical trials include P-PSMA-101 with or without rimiducid (NCT04249947), PSMA-specific CAR-T (NCT04053062), anti-PSCACAR-41BB/TCRzeta-CD19t expressing CAR-T (NCT03873805), BPX-601 anti-PSCA CAR-T with rimiducid (NCT02744287), and anti-EpCAM-CAR-CD3zetaCD28 CAR-T (NCT03013712).

\subsection{Bi-Specific T-cell Engagers (BiTEs)}

Bi-Specific T-cell Engagers (BiTEs) are recombinant fusion proteins that have two linked, single-chain variable fragments (scFvs) from two different antibodies, one of which binds to T cells through a cell-surface receptor such as CD3, and the other that targets a tumor-specific antigen
[97]. BiTEs are independent of MHC haplotype and therefore are 'off-the-shelf' therapy [97]. Pasotuxizumab is a PSMA-targeting BiTE that has been evaluated in a phase I dose-escalation study (NCT01723475). Of the 16 patients enrolled, three had a $\geq 50 \%$ PSA response and there were two long-term responders [98]. Other notable BiTEs in clinical trials include HPN424 (NCT03577028), JNJ-63898081 (NCT03926013), and AMG 160 (NCT03792841), which are PSMA-targeting BiTEs, and AMG 509 (NCT04221542), which is directed towards six transmembrane epithelial antigens of the prostate 1 (STEAP1) [99]. As of July 2020, the phase I trial of AMG 160 treatment in MCRPC was found to be tolerable and efficacious, with cytokine release syndrome (CRS) being the most common AE (all-grade, approximately $90 \%$; grade 3 , approximately $25 \%$; and no grade 4 or 5 CRS) [100]. The confirmed PSA responses and objective responses were observed in $27 \%$ and $13 \%$ of patients, respectively [100].

\subsection{Targeting the Adenosine Pathway}

Elevated adenosine level is associated with an immunosuppressive tumor microenvironment and can be targeted by blocking adenosine $\mathrm{A} 2 \mathrm{~A}$ and $\mathrm{A} 2 \mathrm{~B}$ receptors or antibodies targeting ecto-nucleotidases CD73 and CD39 involved in adenosine formation [101]. In a phase I clinical trial, AZD4635, an adenosine A2A receptor antagonist, showed responses either as a single agent or in combination with durvalumab [102]. A phase I trial is evaluating ciforadenant, another adenosine A2A receptor antagonist, as a single agent and in combination with atezolizumab in patients with mCRPC. Available preliminary results showed one partial response with combination treatment among 14 evaluate patients, along with a clinical benefit rate of 57\% [103]. Another combination regimen of NIR178 (an A2A receptor antagonist) and PDR001 (anti-PD-1 monoclonal antibody) is being examined in a phase II trial of immunotherapy-naïve mCRPC patients, with an estimated completion in 2021 (NCT03207867).

\subsection{Miscellaneous Agents}

TGF $\beta$ receptor inhibitors such as galunisertib (NCT02452008) and PF-06952229 (NCT03685591) are being evaluated in patients with $\mathrm{mCRPC}$, and radium-223 is also being evaluated in combination with pembrolizumab (NCT03093428) and nivolumab (NCT04109729) in patients with mCRPC. Furthermore, NCT04116775 is evaluating fecal microbiota transplant with pembrolizumab in patients with $\mathrm{mCRPC}$. Other agents that are being evaluated in combination with PD-1-directed therapies in the MCRPC setting include ipatasertib (AKT inhibitor; NCT03673787), isatuximab (anti-CD38 antibody; NCT03367819), naptumomab 
(5T4-targeted immunotoxin; NCT03983954), GB 1275 (CD11b agonist; NCT04060342), utomilumab (4-1BB antibody; NCT03217747), and PF-4518600 (OX40 receptor agonist; NCT03217747) [104].

\section{Conclusions}

At present, several clinical trials are evaluating immunotherapies either as a single agent or in combination treatment regimens. Increasing focus is being placed on immune checkpoint inhibitors in various combinations, adenosine receptor antagonists, adoptive cell transfer, and bispecific monoclonal antibodies in the hope of increasing the response in patients with prostate cancer, especially in the mCRPC setting. Despite evidence of immune checkpoint inhibitor activity in preclinical studies, clinical trials examining the efficacies of immunotherapies in the mCRPC setting have not yielded promising results. Potential reasons include PTEN loss leading to altered interferon-1 signaling, decreased MHC-1 expression, low tumor mutational burden, and minimal T-cell infiltration [1]. Such observations have led to the classification of prostate cancer as a 'cold' tumor. Current guidelines do recommend treatment with immune checkpoint inhibitors for patients with MSI-H/ dMMR mCRPC, although these patients constitute a very small minority of patients in clinical practice [16]. The way forward includes exploring pathways to turn prostate cancer into a 'hot' tumor by altering the tumor microenvironment.

\section{Declarations}

Funding No external funding was used in the preparation of this manuscript.

Conflicts of Interest/Competing Interests Neeraj Agarwal has received consultancy fees from Astellas, AstraZeneca, Bayer, Bristol Myers Squibb, Clovis, Eisai, Eli Lilly, EMD Serono, Exelixis, Foundation Medicine, Genentech, Janssen, Merck, Nektar, Novartis, Pfizer, Pharmacyclics, and Seattle Genetics, and institutional research funding from AstraZeneca, Bavarian Nordic, Bayer, Bristol Myers Squibb, Calithera, Celldex, Clovis, Eisai, Eli Lilly, EMD Serono, Exelixis, Genentech, GlaxoSmithKline, Immunomedics, Janssen, Medivation, Merck, Nektar, New Link Genetics, Novartis, Pfizer, Prometheus, Rexahn, Roche, Sanofi, Seattle Genetics, Takeda, and Tracon. Roberto Nussenzveig has received advisory fees from Tempus. Nityam Rathi, Taylor Ryan McFarland, and Umang Swami declare that they have no conflicts of interest.

Ethics Approval Not applicable.

Consent to Participate Not applicable.

Consent for Publication Not applicable.

Availability of Data and Material Not applicable.
Code Availability Not applicable.

Author Contributions Study conception and design: NR, NA, RN, TRM, and US. Acquisition of data: NR, NA, and US. Analysis and interpretation of data: NR, NA, RN, TRM, and US. Drafting of the manuscript: NR, NA, and US. Critical revision: NR, NA, RN, TRM, and US.

Open Access This article is licensed under a Creative Commons Attribution-NonCommercial 4.0 International License, which permits any non-commercial use, sharing, adaptation, distribution and reproduction in any medium or format, as long as you give appropriate credit to the original author(s) and the source, provide a link to the Creative Commons licence, and indicate if changes were made. The images or other third party material in this article are included in the article's Creative Commons licence, unless indicated otherwise in a credit line to the material. If material is not included in the article's Creative Commons licence and your intended use is not permitted by statutory regulation or exceeds the permitted use, you will need to obtain permission directly from the copyright holder. To view a copy of this licence, visit http://creativecommons.org/licenses/by-nc/4.0/.

\section{References}

1. Vitkin N, Nersesian S, Siemens DR, Koti M. The tumor immune contexture of prostate cancer. Front Immunol. 2019;10:603. https ://doi.org/10.3389/fimmu.2019.00603.

2. Singh P, Pal SK, Alex A, Agarwal N. Development of PROSTVAC immunotherapy in prostate cancer. Future Oncol. 2015;11(15):2137-48. https://doi.org/10.2217/fon.15.120.

3. Madan RA, Heery CR, Gulley JL. Poxviral-based vaccine elicits immunologic responses in prostate cancer patients. Oncoimmunology. 2014;3:e28611. https://doi.org/10.4161/onci.28611.

4. Hodge JW, Sabzevari H, Yafal AG, Gritz L, Lorenz MG, Schlom J. A triad of costimulatory molecules synergize to amplify T-cell activation. Cancer Res. 1999;59(22):5800-7.

5. Correale P, Walmsley K, Zaremba S, Zhu M, Schlom J, Tsang $\mathrm{KY}$. Generation of human cytolytic T lymphocyte lines directed against prostate-specific antigen (PSA) employing a PSA oligoepitope peptide. J Immunol. 1998;161(6):3186-94.

6. Terasawa H, Tsang KY, Gulley J, Arlen P, Schlom J. Identification and characterization of a human agonist cytotoxic T-lymphocyte epitope of human prostate-specific antigen. Clin Cancer Res. 2002;8(1):41-53.

7. Gulley J, Chen AP, Dahut W, Arlen PM, Bastian A, Steinberg $\mathrm{SM}$, et al. Phase I study of a vaccine using recombinant vaccinia virus expressing PSA (rV-PSA) in patients with metastatic androgen-independent prostate cancer. Prostate. 2002;53(2):109-17. https://doi.org/10.1002/pros.10130.

8. Arlen PM, Skarupa L, Pazdur M, Seetharam M, Tsang KY, Grosenbach DW, et al. Clinical safety of a viral vector based prostate cancer vaccine strategy. J Urol. 2007;178(4 Pt 1):151520. https://doi.org/10.1016/j.juro.2007.05.117.

9. Kantoff PW, Schuetz TJ, Blumenstein BA, Glode LM, Bilhartz DL, Wyand $M$, et al. Overall survival analysis of a phase II randomized controlled trial of a Poxviral-based PSA-targeted immunotherapy in metastatic castration-resistant prostate cancer. J Clin Oncol. 2010;28(7):1099-105. https://doi.org/10.1200/ JCO.2009.25.0597.

10. Gulley JL, Borre M, Vogelzang NJ, Ng S, Agarwal N, Parker CC, et al. Phase III trial of PROSTVAC in asymptomatic or minimally symptomatic metastatic castration-resistant prostate cancer. 
J Clin Oncol. 2019;37(13):1051-61. https://doi.org/10.1200/ JCO.18.02031.

11. Handy CE, Antonarakis ES. Sipuleucel-T for the treatment of prostate cancer: novel insights and future directions. Future Oncol. 2018;14(10):907-17. https://doi.org/10.2217/ fon-2017-0531.

12. Higano CS, Schellhammer PF, Small EJ, Burch PA, Nemunaitis $\mathrm{J}$, Yuh L, et al. Integrated data from 2 randomized, double-blind, placebo-controlled, phase 3 trials of active cellular immunotherapy with sipuleucel-T in advanced prostate cancer. Cancer. 2009;115(16):3670-9. https://doi.org/10.1002/cncr.24429.

13. Kantoff PW, Higano CS, Shore ND, Berger ER, Small EJ, Penson DF, et al. Sipuleucel-T immunotherapy for castration-resistant prostate cancer. N Engl J Med. 2010;363(5):411-22. https://doi. org/10.1056/NEJMoa1001294.

14. Mark D, Samson DJ, Bonnell CJ, Ziegler KM, Aronson N. Outcomes of sipuleucel-T therapy. Rockville: AHRQ Technology Assessments; 2011.

15. Huber ML, Haynes L, Parker C, Iversen P. Interdisciplinary critique of sipuleucel-T as immunotherapy in castration-resistant prostate cancer. J Natl Cancer Inst. 2012;104(4):273-9. https:// doi.org/10.1093/jnci/djr514.

16. National Comprehensive Cancer Network. Prostate Cancer (Version 2.2020). http://www.nccn.org/professionals/physician_gls/ pdf/prostate.pdf. Accessed 23 Jun 2020.

17. Rosser CJ, Hirasawa Y, Acoba JD, Tamura DJ, Pal SK, Huang J et al. Phase Ib study assessing different sequencing regimens of atezolizumab (anti-PD-L1) and sipuleucel-T (SipT)in patients who have asymptomatic or minimally symptomatic metastatic castrate resistant prostate cancer. J Clin Oncol. 2020;38(15 Suppl):e17564-e. https://doi.org/10.1200/jco.2020.38.15_suppl .e17564.

18. Topalian SL, Drake CG, Pardoll DM. Immune checkpoint blockade: a common denominator approach to cancer therapy. Cancer Cell. 2015;27(4):450-61. https://doi.org/10.1016/j.ccell .2015.03.001.

19. Sharma A, Subudhi SK, Blando J, Scutti J, Vence L, Wargo J, et al. Anti-CTLA-4 immunotherapy does not deplete FOXP3(+) regulatory $\mathrm{T}$ cells (Tregs) in human cancers. Clin Cancer Res. 2019;25(4):1233-8. https://doi.org/10.1158/1078-0432. CCR-18-0762.

20. Madan RA, Mohebtash M, Arlen PM, Vergati M, Rauckhorst M, Steinberg SM, et al. Ipilimumab and a poxviral vaccine targeting prostate-specific antigen in metastatic castrationresistant prostate cancer: a phase 1 dose-escalation trial. Lancet Oncol. 2012;13(5):501-8. https://doi.org/10.1016/S1470 -2045(12)70006-2.

21. van den Eertwegh AJ, Versluis J, van den Berg HP, Santegoets SJ, van Moorselaar RJ, van der Sluis TM, et al. Combined immunotherapy with granulocyte-macrophage colony-stimulating factor-transduced allogeneic prostate cancer cells and ipilimumab in patients with metastatic castration-resistant prostate cancer: a phase 1 dose-escalation trial. Lancet Oncol. 2012;13(5):509-17. https://doi.org/10.1016/S1470-2045(12)70007-4.

22. Slovin SF, Higano CS, Hamid O, Tejwani S, Harzstark A, Alum$\mathrm{kal} \mathrm{JJ}$, et al. Ipilimumab alone or in combination with radiotherapy in metastatic castration-resistant prostate cancer: results from an open-label, multicenter phase I/II study. Ann Oncol. 2013;24(7):1813-21. https://doi.org/10.1093/annonc/mdt107.

23. Kwon ED, Drake CG, Scher HI, Fizazi K, Bossi A, van den Eertwegh AJ, et al. Ipilimumab versus placebo after radiotherapy in patients with metastatic castration-resistant prostate cancer that had progressed after docetaxel chemotherapy (CA184-043): a multicentre, randomised, double-blind, phase 3 trial. Lancet Oncol. 2014;15(7):700-12. https://doi.org/10.1016/S1470 $-2045(14) 70189-5$.
24. Fizazi K, Drake CG, Beer TM, Kwon ED, Scher HI, Gerritsen WR et al. Final analysis of the ipilimumab versus placebo following radiotherapy phase III trial in postdocetaxel metastatic castration-resistant prostate cancer identifies an excess of long-term survivors. Eur Urol. Epub 15 Aug 2020. https://doi. org/10.1016/j.eururo.2020.07.032.

25. Gevensleben H, Dietrich D, Golletz C, Steiner S, Jung M, Thiesler T, et al. The immune checkpoint regulator PD-L1 is highly expressed in aggressive primary prostate cancer. Clin Cancer Res. 2016;22(8):1969-77. https://doi.org/10.1158/10780432.CCR-15-2042.

26. Hansen AR, Massard C, Ott PA, Haas NB, Lopez JS, Ejadi $\mathrm{S}$, et al. Pembrolizumab for advanced prostate adenocarcinoma: findings of the KEYNOTE-028 study. Ann Oncol. 2018;29(8):1807-13. https://doi.org/10.1093/annonc/mdy232.

27. Antonarakis ES, Piulats JM, Gross-Goupil M, Goh J, Ojamaa K, Hoimes CJ, et al. Pembrolizumab for treatment-refractory metastatic castration-resistant prostate cancer: multicohort, open-label phase II KEYNOTE-199 study. J Clin Oncol. 2020;38(5):395405. https://doi.org/10.1200/JCO.19.01638.

28. Antonarakis ES, Rodriguez JMMP, Gross-Goupil M, Goh JC, Vaishampayan UN, Wit RD, et al. Biomarker analysis from the KEYNOTE-199 trial of pembrolizumab in patients (pts) with docetaxel-refractory metastatic castration-resistant prostate cancer (mCRPC). J Clin Oncol. 2020;38(15 Suppl):5526. https://doi. org/10.1200/JCO.2020.38.15_suppl.5526.

29. Curran MA, Montalvo W, Yagita H, Allison JP. PD-1 and CTLA-4 combination blockade expands infiltrating T cells and reduces regulatory $\mathrm{T}$ and myeloid cells within B16 melanoma tumors. Proc Natl Acad Sci USA. 2010;107(9):4275-80. https:// doi.org/10.1073/pnas.0915174107.

30. Wolchok JD, Chiarion-Sileni V, Gonzalez R, Rutkowski P, Grob JJ, Cowey CL, et al. Overall survival with combined nivolumab and ipilimumab in advanced melanoma. N Engl $\mathrm{J}$ Med. 2017;377(14):1345-56. https://doi.org/10.1056/NEJMo a1709684.

31. Motzer RJ, Tannir NM, McDermott DF, Aren Frontera O, Melichar B, Choueiri TK, et al. Nivolumab plus ipilimumab versus sunitinib in advanced renal-cell carcinoma. N Engl J Med. 2018;378(14):1277-90. https://doi.org/10.1056/NEJMoa1712 126.

32. Hellmann MD, Ciuleanu TE, Pluzanski A, Lee JS, Otterson GA, Audigier-Valette C, et al. Nivolumab plus ipilimumab in lung cancer with a high tumor mutational burden. N Engl J Med. 2018;378(22):2093-104. https://doi.org/10.1056/NEJMoa1801 946.

33. Sharma P, Pachynski RK, Narayan V, Flechon A, Gravis G, Galsky MD, et al. Initial results from a phase II study of nivolumab (NIVO) plus ipilimumab (IPI) for the treatment of metastatic castration-resistant prostate cancer (mCRPC; CheckMate 650). J Clin Oncol. 2019;37(7 Suppl):142. https://doi.org/10.1200/ JCO.2019.37.7_suppl.142.

34. Jacobson EL, Smith JY, Wielckens K, Hilz H, Jacobson MK. Cellular recovery of dividing and confluent C3H10T1/2 cells from $\mathrm{N}$-methyl-N'-nitro-N-nitrosoguanidine in the presence of ADP-ribosylation inhibitors. Carcinogenesis. 1985;6(5):715-8. https://doi.org/10.1093/carcin/6.5.715.

35. Murai J, Huang SY, Das BB, Renaud A, Zhang Y, Doroshow $\mathrm{JH}$, et al. Trapping of PARP1 and PARP2 by clinical PARP inhibitors. Cancer Res. 2012;72(21):5588-99. https://doi. org/10.1158/0008-5472.CAN-12-2753.

36. Pritchard CC, Mateo J, Walsh MF, De Sarkar N, Abida W, Beltran $\mathrm{H}$, et al. Inherited DNA-repair gene mutations in men with metastatic prostate cancer. N Engl J Med. 2016;375(5):443-53. https://doi.org/10.1056/NEJMoa1603144. 
37. Robinson D, Van Allen EM, Wu YM, Schultz N, Lonigro RJ, Mosquera JM, et al. Integrative clinical genomics of advanced prostate cancer. Cell. 2015;161(5):1215-28. https://doi. org/10.1016/j.cell.2015.05.001.

38. Abida W, Cheng ML, Armenia J, Middha S, Autio KA, Vargas HA, et al. Analysis of the prevalence of microsatellite instability in prostate cancer and response to immune checkpoint blockade. JAMA Oncol. 2019;5(4):471-8. https://doi.org/10.1001/jamao ncol.2018.5801.

39. US FDA. Hematology/Oncology (Cancer) Approvals \& Safety Notifications. https://www.fda.gov/drugs/resources-informatio n-approved-drugs/hematologyoncology-cancer-approvals-safet y-notifications. Accessed 23 Jun 2020.

40. Ding L, Kim HJ, Wang Q, Kearns M, Jiang T, Ohlson CE et al. PARP Inhibition elicits STING-dependent antitumor immunity in brca1-deficient ovarian cancer. Cell Rep. 2018;25(11):2972-80 e5. https://doi.org/10.1016/j.celrep.2018.11.054.

41. Lee EK, Konstantinopoulos PA. Combined PARP and immune checkpoint inhibition in ovarian cancer. Trends Cancer. 2019;5(9):524-8. https://doi.org/10.1016/j.trecan.2019.06.004.

42. Yu EY, Piulats JM, Gravis G, Laguerre B, Arija JAA, Oudard S, et al. KEYNOTE-365 cohort A updated results: pembrolizumab (pembro) plus olaparib in docetaxel-pretreated patients (pts) with metastatic castration-resistant prostate cancer (mCRPC). J Clin Oncol. 2020;38(6 Suppl):100. https://doi.org/10.1200/ JCO.2020.38.6_suppl.100.

43. Yu EY, Rodriguez JMMP, Gravis G, Laguerre B, Arija JAA, Oudard S, et al. Pembrolizumab (pembro) plus olaparib in patients (pts) with docetaxel-pretreated metastatic castrationresistant prostate cancer (mCRPC): KEYNOTE-365 cohort A efficacy, safety, and biomarker results. J Clin Oncol. 2020;38(15 Suppl):5544. https://doi.org/10.1200/JCO.2020.38.15_suppl .5544 .

44. Yu EY, Park SH, Huang Y-H, Bennamoun M, Xu L, Kim J et al. Phase III study of pembrolizumab (pembro) plus olaparib versus enzalutamide (enza) or abiraterone acetate (abi) in patients (pts) with metastatic castration-resistant prostate cancer (mCRPC) who progressed on chemotherapy: KEYLYNK-010. J Clin Oncol. 2020;38(6 Suppl):TPS256. https://doi.org/10.1200/ jco.2020.38.6_suppl.tps256.

45. Fizazi K, Drake CG, Shaffer DR, Pachynski R, Saad F, Ciprotti $\mathrm{M}$ et al. An open-label, phase 2 study of nivolumab in combination with either rucaparib, docetaxel, or enzalutamide in men with castration-resistant metastatic prostate cancer (mCRPC; CheckMate 9KD). J Clin Oncol. 2018;36(15 Suppl):TPS3126. https://doi.org/10.1200/jco.2018.36.15_suppl.tps3126.

46. Karzai F, VanderWeele D, Madan RA, Owens H, Cordes LM, Hankin A, et al. Activity of durvalumab plus olaparib in metastatic castration-resistant prostate cancer in men with and without DNA damage repair mutations. J Immunother Cancer. 2018;6(1):141. https://doi.org/10.1186/s40425-018-0463-2.

47. Gabrilovich DI, Chen HL, Girgis KR, Cunningham HT, Meny GM, Nadaf S, et al. Production of vascular endothelial growth factor by human tumors inhibits the functional maturation of dendritic cells. Nat Med. 1996;2(10):1096-103. https://doi. org/10.1038/nm1096-1096.

48. Benkhoucha M, Santiago-Raber ML, Schneiter G, Chofflon M, Funakoshi H, Nakamura T, et al. Hepatocyte growth factor inhibits CNS autoimmunity by inducing tolerogenic dendritic cells and CD25 + Foxp3 + regulatory T cells. Proc Natl Acad Sci USA. 2010;107(14):6424-9. https://doi.org/10.1073/pnas.0912437107

49. Wada J, Suzuki H, Fuchino R, Yamasaki A, Nagai S, Yanai K, et al. The contribution of vascular endothelial growth factor to the induction of regulatory T-cells in malignant effusions. Anticancer Res. 2009;29(3):881-8.

50. Heine A, Held SA, Bringmann A, Holderried TA, Brossart P. Immunomodulatory effects of anti-angiogenic drugs. Leukemia. 2011;25(6):899-905. https://doi.org/10.1038/leu.2011.24.

51. Ozao-Choy J, Ma G, Kao J, Wang GX, Meseck M, Sung M, et al. The novel role of tyrosine kinase inhibitor in the reversal of immune suppression and modulation of tumor microenvironment for immune-based cancer therapies. Cancer Res. 2009;69(6):2514-22. https://doi.org/10.1158/0008-5472. CAN-08-4709.

52. Navis AC, Bourgonje A, Wesseling P, Wright A, Hendriks W, Verrijp K, et al. Effects of dual targeting of tumor cells and stroma in human glioblastoma xenografts with a tyrosine kinase inhibitor against c-MET and VEGFR2. PLoS One. 2013;8(3):e58262. https://doi.org/10.1371/journal.pone.00582 62.

53. Nguyen HM, Ruppender N, Zhang X, Brown LG, Gross TS, Morrissey C, et al. Cabozantinib inhibits growth of androgensensitive and castration-resistant prostate cancer and affects bone remodeling. PLoS One. 2013;8(10):e78881. https://doi. org/10.1371/journal.pone.0078881.

54. Kwilas AR, Ardiani A, Donahue RN, Aftab DT, Hodge JW. Dual effects of a targeted small-molecule inhibitor (cabozantinib) on immune-mediated killing of tumor cells and immune tumor microenvironment permissiveness when combined with a cancer vaccine. J Transl Med. 2014;12:294. https://doi.org/10.1186/ s12967-014-0294-y.

55. Agarwal N, Loriot Y, McGregor BA, Dreicer R, Dorff TB, Maughan BL, et al. Cabozantinib (C) in combination with atezolizumab (A) in patients (pts) with metastatic castrationresistant prostate cancer (mCRPC): results of Cohort 6 of the COSMIC-021 Study. J Clin Oncol. 2020;38(6 Suppl):139. https ://doi.org/10.1200/JCO.2020.38.6_suppl.139.

56. Lonergan PE, Tindall DJ. Androgen receptor signaling in prostate cancer development and progression. J Carcinog. 2011;10:20. https://doi.org/10.4103/1477-3163.83937.

57. Saad F. Evidence for the efficacy of enzalutamide in postchemotherapy metastatic castrate-resistant prostate cancer. Ther Adv Urol. 2013;5(4):201-10. https://doi.org/10.1177/1756287213 490054.

58. Scher HI, Fizazi K, Saad F, Taplin ME, Sternberg CN, Miller $\mathrm{K}$, et al. Increased survival with enzalutamide in prostate cancer after chemotherapy. N Engl J Med. 2012;367(13):1187-97. https ://doi.org/10.1056/NEJMoa1207506.

59. Beer TM, Armstrong AJ, Rathkopf DE, Loriot Y, Sternberg $\mathrm{CN}$, Higano CS, et al. Enzalutamide in metastatic prostate cancer before chemotherapy. N Engl J Med. 2014;371(5):424-33. https://doi.org/10.1056/NEJMoa1405095.

60. Ardiani A, Farsaci B, Rogers CJ, Protter A, Guo Z, King TH, et al. Combination therapy with a second-generation androgen receptor antagonist and a metastasis vaccine improves survival in a spontaneous prostate cancer model. Clin Cancer Res. 2013;19(22):6205-18. https://doi.org/10.1158/1078-0432. CCR-13-1026.

61. Ardiani A, Gameiro SR, Kwilas AR, Donahue RN, Hodge JW. Androgen deprivation therapy sensitizes prostate cancer cells to T-cell killing through androgen receptor dependent modulation of the apoptotic pathway. Oncotarget. 2014;5(19):933548. https://doi.org/10.18632/oncotarget.2429.

62. McDermott R, Graff JN, Antonarakis ES, Hoimes CJ, Tagawa ST, Hwang C, et al. 568-KEYNOTE-199 cohorts 4 and 5: pembrolizumab (pembro) plus enzalutamide (enza) for enza-resistant metastatic castration-resistant prostate cancer (mCRPC). 
Eur Urol Open Sci. 2020;19:e885-6. https://doi.org/10.1016/ S2666-1683(20)33171-2.

63. Conter HJ, Shore ND, Berry WR, Fong PCC, Rodriguez JMMP, Appleman LJ, et al. Pembrolizumab (pembro) plus enzalutamide (enza) in patients (pts) with abiraterone acetate (abi)-pretreated metastatic castration-resistant prostate cancer (mCRPC): KEYNOTE-365 cohort C efficacy, safety, and biomarker results. J Clin Oncol. 2020;38(15 Suppl):5545. https:// doi.org/10.1200/JCO.2020.38.15_suppl.5545.

64. Sweeney CJ, Gillessen S, Rathkopf D, Matsubara N, Drake C, Fizazi K et al. IMbassador250: A phase III trial comparing atezolizumab with enzalutamide vs enzalutamide alone in patients with metastatic castration-resistant prostate cancer (mCRPC) [abstract no. CT014]. Presented at the 2020 AACR Virtual Annual Meeting: 27 Apr 2020.

65. Tannock IF, de Wit R, Berry WR, Horti J, Pluzanska A, Chi $\mathrm{KN}$, et al. Docetaxel plus prednisone or mitoxantrone plus prednisone for advanced prostate cancer. N Engl J Med. 2004;351(15):1502-12. https://doi.org/10.1056/NEJMoa0407 20.

66. Pienta KJ. Preclinical mechanisms of action of docetaxel and docetaxel combinations in prostate cancer. Semin Oncol. 2001;28(4 Suppl 15):3-7. https://doi.org/10.1016/s0093-7754(01)90148-4.

67. Chan OT, Yang LX. The immunological effects of taxanes. Cancer Immunol Immunother. 2000;49(4-5):181-5. https://doi. org/10.1007/s002620000122.

68. Hodge JW, Garnett CT, Farsaci B, Palena C, Tsang KY, Ferrone $\mathrm{S}$, et al. Chemotherapy-induced immunogenic modulation of tumor cells enhances killing by cytotoxic $\mathrm{T}$ lymphocytes and is distinct from immunogenic cell death. Int $\mathbf{J}$ Cancer. 2013;133(3):624-36. https://doi.org/10.1002/ijc.28070.

69. Taghizadeh H, Marhold M, Tomasich E, Udovica S, Merchant A, Krainer M. Immune checkpoint inhibitors in mCRPCrationales, challenges and perspectives. Oncoimmunology. 2019;8(11):e1644109. https://doi.org/10.1080/21624 02X.2019.1644109.

70. Garnett CT, Schlom J, Hodge JW. Combination of docetaxel and recombinant vaccine enhances T-cell responses and antitumor activity: effects of docetaxel on immune enhancement. Clin Cancer Res. 2008;14(11):3536-44. https://doi.org/10.1158/10780432.CCR-07-4025.

71. Sridhar SS, Kolinsky MP, Gravis G, Mourey L, Rodriguez JMMP, Romano E, et al. Pembrolizumab (pembro) plus docetaxel and prednisone in patients (pts) with abiraterone acetate (abi) or enzalutamide (enza)-pretreated metastatic castrationresistant prostate cancer (mCRPC): KEYNOTE-365 cohort B efficacy, safety and biomarker results. J Clin Oncol. 2020;38(15 Suppl):5550. https://doi.org/10.1200/JCO.2020.38.15_suppl .5550 .

72. Fizazi K, Gonzalez Mella P, Castellano D, Minatta JN, Rezazadeh Kalebasty A, Shaffer D, et al. LBA52-efficacy and safety of nivolumab in combination with docetaxel in men with metastatic castration-resistant prostate cancer in CheckMate 9KD. Ann Oncol. 2019;30:v885-6. https://doi.org/10.1093/annonc/ mdz394.045.

73. O'Donoghue JA, Bardies M, Wheldon TE. Relationships between tumor size and curability for uniformly targeted therapy with beta-emitting radionuclides. J Nucl Med. 1995;36(10):1902-9.

74. Eiber M, Fendler WP, Rowe SP, Calais J, Hofman MS, Maurer $\mathrm{T}$, et al. Prostate-specific membrane antigen ligands for imaging and therapy. J Nucl Med. 2017;58(Suppl 2):67S-76S. https://doi. org/10.2967/jnumed.116.186767.

75. Bostwick DG, Pacelli A, Blute M, Roche P, Murphy GP. Prostate specific membrane antigen expression in prostatic intraepithelial neoplasia and adenocarcinoma: a study of 184 cases. Cancer. 1998;82(11):2256-61. https://doi.org/10.1002/ (sici) 1097-0142(19980601)82:11\%3c2256:aid-cncr2 $2 \% 3 \mathrm{e} 3.0 . \mathrm{co} ; 2$-s.

76. Liu H, Rajasekaran AK, Moy P, Xia Y, Kim S, Navarro V, et al. Constitutive and antibody-induced internalization of prostatespecific membrane antigen. Cancer Res. 1998;58(18):4055-60.

77. Karan D, Chen SJ, Johansson SL, Singh AP, Paralkar VM, Lin MF, et al. Dysregulated expression of MIC-1/PDF in human prostate tumor cells. Biochem Biophys Res Commun. 2003;305(3):598-604. https://doi.org/10.1016/s0006 $-291 \times(03) 00823-4$.

78. Bauer S, Groh V, Wu J, Steinle A, Phillips JH, Lanier LL, et al. Activation of NK cells and T cells by NKG2D, a receptor for stress-inducible MICA. Science. 1999;285(5428):727-9. https ://doi.org/10.1126/science.285.5428.727.

79. Raulet DH. Roles of the NKG2D immunoreceptor and its ligands. Nat Rev Immunol. 2003;3(10):781-90. https://doi.org/10.1038/ nri1199.

80. Groh V, Wu J, Yee C, Spies T. Tumour-derived soluble MIC ligands impair expression of NKG2D and T-cell activation. Nature. 2002;419(6908):734-8. https://doi.org/10.1038/natur e01112.

81. Salih HR, Rammensee HG, Steinle A. Cutting edge: down-regulation of MICA on human tumors by proteolytic shedding. J Immunol. 2002;169(8):4098-102. https://doi.org/10.4049/jimmu nol.169.8.4098.

82. Wu JD, Higgins LM, Steinle A, Cosman D, Haugk K, Plymate SR. Prevalent expression of the immunostimulatory MHC class I chain-related molecule is counteracted by shedding in prostate cancer. J Clin Invest. 2004;114(4):560-8. https://doi. org/10.1172/JCI22206.

83. Lu S, Zhang J, Liu D, Li G, Staveley-O'Carroll KF, Li Z, et al. Nonblocking monoclonal antibody targeting soluble MIC revamps endogenous innate and adaptive antitumor responses and eliminates primary and metastatic tumors. Clin Cancer Res. 2015;21(21):4819-30. https://doi.org/10.1158/1078-0432. CCR-15-0845.

84. Wu J. Antibody targeting soluble NKG2D ligand sMIC refuels and invigorates the endogenous immune system to fight cancer. Oncoimmunology. 2016;5(3):e1095434. https://doi. org/10.1080/2162402X.2015.1095434.

85. Zhang J, Liu D, Li G, Staveley-O'Carroll KF, Graff JN, Li $Z$, et al. Antibody-mediated neutralization of soluble MIC significantly enhances CTLA4 blockade therapy. Sci Adv. 2017;3(5):e1602133. https://doi.org/10.1126/sciadv.1602133.

86. Zhang J, Larrocha PS, Zhang B, Wainwright D, Dhar P, Wu JD. Antibody targeting tumor-derived soluble NKG2D ligand sMIC provides dual co-stimulation of CD8 T cells and enables sMIC(+) tumors respond to PD1/PD-L1 blockade therapy. J Immunother Cancer. 2019;7(1):223. https://doi.org/10.1186/ s40425-019-0693-y.

87. Almasbak H, Aarvak T, Vemuri MC. CAR T cell therapy: a game changer in cancer treatment. J Immunol Res. 2016;2016:5474602. https://doi.org/10.1155/2016/5474602.

88. Zuccolotto G, Fracasso G, Merlo A, Montagner IM, Rondina $\mathrm{M}$, Bobisse S, et al. PSMA-specific CAR-engineered T cells eradicate disseminated prostate cancer in preclinical models. PLoS One. 2014;9(10):e109427. https://doi.org/10.1371/journ al.pone.0109427.

89. June CH, O'Connor RS, Kawalekar OU, Ghassemi S, Milone MC. CAR T cell immunotherapy for human cancer. Science. 2018;359(6382):1361-5. https://doi.org/10.1126/science.aar67 11.

90. Porter DL, Levine BL, Kalos M, Bagg A, June CH. Chimeric antigen receptor-modified $\mathrm{T}$ cells in chronic lymphoid leukemia. N Engl J Med. 2011;365(8):725-33. https://doi.org/10.1056/ NEJMoa1103849. 
91. Grupp SA, Kalos M, Barrett D, Aplenc R, Porter DL, Rheingold $\mathrm{SR}$, et al. Chimeric antigen receptor-modified $\mathrm{T}$ cells for acute lymphoid leukemia. N Engl J Med. 2013;368(16):1509-18. https ://doi.org/10.1056/NEJMoa1215134.

92. Slovin SF, Wang X, Hullings M, Arauz G, Bartido S, Lewis JS, et al. Chimeric antigen receptor $(\mathrm{CAR}+)$ modified $\mathrm{T}$ cells targeting prostate-specific membrane antigen (PSMA) in patients (pts) with castrate metastatic prostate cancer (CMPC). J Clin Oncol. 2013;31(6 Suppl):72. https://doi.org/10.1200/jco.2013.31.6_ suppl.72.

93. Siegel PM, Massague J. Cytostatic and apoptotic actions of TGF-beta in homeostasis and cancer. Nat Rev Cancer. 2003;3(11):807-21. https://doi.org/10.1038/nrc1208.

94. Massague J. TGFbeta in cancer. Cell. 2008;134(2):215-30. https ://doi.org/10.1016/j.cell.2008.07.001.

95. Kloss CC, Lee J, Zhang A, Chen F, Melenhorst JJ, Lacey SF, et al. Dominant-negative TGF-beta receptor enhances PSMAtargeted human CAR T cell proliferation and augments prostate cancer eradication. Mol Ther. 2018;26(7):1855-66. https://doi. org/10.1016/j.ymthe.2018.05.003.

96. Narayan V, Gladney W, Plesa G, Vapiwala N, Carpenter E, Maude SL et al. A phase I clinical trial of PSMA-directed/ TGF $\beta$-insensitive CAR-T cells in metastatic castration-resistant prostate cancer. J Clin Oncol. 2019;37(7_suppl):TPS347. https ://doi.org/10.1200/jco.2019.37.7_suppl.tps347.

97. Slaney CY, Wang P, Darcy PK, Kershaw MH. CARs versus BiTEs: a comparison between $\mathrm{T}$ cell-redirection strategies for cancer treatment. Cancer Discov. 2018;8(8):924-34. https://doi. org/10.1158/2159-8290.CD-18-0297.

98. Hummel H-D, Kufer P, Grüllich C, Deschler-Baier B, Chatterjee M, Goebeler M-E, et al. Phase 1 study of pasotuxizumab (BAY
2010112), a PSMA-targeting Bispecific T cell Engager (BiTE) immunotherapy for metastatic castration-resistant prostate cancer (mCRPC). J Clin Oncol. 2019;37(15 Suppl):5034. https://doi. org/10.1200/JCO.2019.37.15_suppl.5034.

99. Fay EK, Graff JN. Immunotherapy in prostate cancer. Cancers (Basel). 2020;12(7):1752. https://doi.org/10.3390/cancers120 71752.

100. Tran B, Horvath L, Dorff T, Rettig M, Lolkema MP, Machiels JP, et al. 6090 Results from a phase I study of AMG 160, a halflife extended (HLE), PSMA-targeted, bispecific T-cell engager $\left(\mathrm{BiTE}^{\circledR}\right)$ immune therapy for metastatic castration-resistant prostate cancer (mCRPC). Ann Oncol. 2020;31:S507. https:// doi.org/10.1016/j.annonc.2020.08.869.

101. Hammami A, Allard D, Allard B, Stagg J. Targeting the adenosine pathway for cancer immunotherapy. Semin Immunol. 2019;42:101304. https://doi.org/10.1016/j.smim.2019.101304.

102. Bendell J, Bauer T, Patel M, Falchook G, Karlix JL, Lim E et al. Abstract CT026: Evidence of immune activation in the firstin-human Phase Ia dose escalation study of the adenosine 2a receptor antagonist, AZD4635, in patients with advanced solid tumors. Cancer Res. 2019;79(13 Suppl):CT026. https://doi. org/10.1158/1538-7445.am2019-ct026.

103. Harshman LC, Chu M, George S, Hughes BGM, Carthon BC, Fong L, et al. Adenosine receptor blockade with ciforadenant \pm atezolizumab in advanced metastatic castration-resistant prostate cancer (mCRPC). J Clin Oncol. 2020;38(6 Suppl):129. https://doi.org/10.1200/JCO.2020.38.6_suppl.129.

104. de Almeida DVP, Fong L, Rettig MB, Autio KA. Immune checkpoint blockade for prostate cancer: Niche role or next breakthrough? Am Soc Clin Oncol Educ Book. 2020;40:1-18. https ://doi.org/10.1200/EDBK_278853. 